\title{
The Value of Invoice Currency Choice in a Volatile Exchange Rate Environment*
}

\author{
Pekka Ahtiala \\ University of Tampere, Finland \\ Yair E. Orgler \\ Tel Aviv University, Israel
}

The paper explores the conditions whereby an exporter can gain a competitive advantage by offering a buyer a contract with a choice of invoice currencies rather than a single currency, and determines the value of such a choice. The model incorporates accounts-payable management with exchangerisk management, taking into account the forward exchange rate and the seller's assumptions about the buyer's initial foreign exchange position, its expectations about the future spot rate, and its risk premium. It demonstrates how the value of a choice depends on these variables, as well as on the market interest rates in the two currencies, and on the implicit conversion factor that the seller uses in pricing in different currencies. Two numerical examples demonstrate that a currency choice can be equivalent to a substantial price cut with commonly observed parameter values. Since an exporter can often offer a choice at a low cost to itself, it can increase profits by raising its product price in return for a choice without hurting its competitiveness. This is particularly relevant when offering the choice to the buyer in a less common currency or when exchange rates are volatile. The results are driven by the fact that the forward exchange rate often deviates substantially from the expected future spot rate, and by transactions costs, which can be considerable for less common currencies.

Keywords: invoice currency choice, payment terms in foreign trade

\section{Introduction}

The reduction of trade barriers and world-wide overcapacity in many

\footnotetext{
${ }^{*}$ We wish to thank two anonymous referees for many useful comments, and The Israel Ministry of Science and the Arts and the Finnish Ministry of Education for financial support.

(Multinational Finance Journal, 1999, vol. 3, no. 1, pp. 1-17)

(CMultinational Finance Society, a nonprofit corporation. All rights reserved.

DOI: $10.17578 / 3-1-1$
} 
industries have substantially increased competition in international trade where exporters compete vigorously in prices, credit terms, delivery schedules, services, and so on. A competitive device that has been almost neglected in the literature, yet has a considerable potential, is a choice of invoice currency. A favorable selection of invoice currencies, especially in less common currencies or when exchange rates are volatile, can be equivalent to a considerable price reduction to the buyer, and yet it can often be achieved at little or no cost to the seller. This pricing policy could be used by an exporter as an integral part of a sophisticated foreign exchange risk management, an activity which has become increasingly important both for exporters and importers.

Exchange risks can be covered by using external and internal hedging methods. The most popular external hedging device is the forward market for foreign exchange. However, the forward rate, determined by covered interest arbitrage, often falls beyond the range in which the firm believes the future spot rate to be, so that covering is either lucrative or prohibitively costly. For instance, the spot exchange rate of the dollar was 143 yen in July 1998, while the 6-month interest rate was $5.65 \%$ in the United States in July and .74\% in Japan. This implied a 6-month forward rate of 139 , whereas the spot rate in January 1999 was 113. In Turkey, for example, the 12-month interest rate was 96\% and the spot dollar exchange rate was 215000 in January 1998, implying a one-year forward rate of 401000 against the dollar. The actual spot rate in January 1999 was 320000 lira. ${ }^{1}$ Thus, wide interest rate spreads are not always followed by exchange rate adjustments and, even when they are, their magnitude and timing are highly uncertain. Indeed, the forward rates have been found to be neither unbiased nor efficient predictors of future spot rates [see Hodrick (1987), Hakkio (1981), and Hansen and Hodrick (1980)]. Of course, exchange rate adjustments affect the value of a contract only if they take place within the contract period. Moreover, the transaction costs of forward contracts - especially for less common currencies — are not

1. For example, the bid-asked spread for a one-year contract for the dollar against the Deutsche mark was .05\% in November 1998, while those of the major currencies against the Finnmark were $.1 \%$, reflecting the imminent introduction of the Euro. The spread of major currencies against the Danish Krona was .3\% at the same time since Denmark did not join the Monetary Union. This indicates that the spreads increase as one moves to less common invoice currencies. The spreads between two less common currencies rise further because the exchange rates are generally determined from their respective rates against the dollar when two half spreads have to be paid. (Source: Merita Bank, Foreign Exchange Department, 17/11/1998.) 
insignificant, although they have decreased in recent years. ${ }^{2}$ In a highly competitive environment, where profit margins are narrow, the effect of such costs on profits cannot be neglected, especially because they go directly to the bottom line. This is another reason why many companies use internal hedging methods and resort to the forward market only after these methods have been exhausted.

Internal hedging procedures such as specification of invoice currency are increasingly used by exporters and importers in different countries for hedging the firm's own exchange position, but less so as a competitive device. ${ }^{3}$ Due to the cost of these methods, complete coverage is generally not optimal. Therefore, a seller and a buyer in an international transaction are likely to have different initial open positions in various currencies, resulting from other foreign exchange transactions. Moreover, an exporter and an importer may have different expectations about the future spot exchange rates at the time of payment. All this leads to the possibility that both the seller and the buyer can gain from the proper selection of the invoice currency.

The literature on invoice currency specification and choice is rather limited. One group of articles concentrates on the selection of a single invoice currency under exchange rate uncertainty [see Magee and Rao (1980) and Bilson $(1983,1987)]$. Another group of articles deals with micro-economic aspects of export pricing with special attention to the relationships between exchange rates, interest rates, credit periods, and prices in the framework of present value calculation [see, for instance, Hekman (1981) and Shapiro (1973)]. A recent paper by Ahtiala and Orgler (1995) suggests that it can be optimal for an exporter to offer customers a choice of invoice currencies and derives the optimal export prices. In doing so, the authors take the buyers' demand functions for

2. A survey conducted by Soenen and Aggarwal (1989) in three European countries (Britain, Belgium, and the Netherlands) shows that while a majority of the corporations surveyed use forward contracts in hedging foreign exchange exposure, they expressed the opinion that the exposure should first be minimized by other means before resorting to external hedging methods. Full hedging was used by only $19 \%$ of the U.K. companies, $26 \%$ of the Netherlands companies, and none by Belgian firms. Overall, $75 \%$ of the responding companies felt that a complete cover is not worth the cost. It should be noted that the only method rated close to forward contracts was the specification of particular currencies for export/import transactions, which is the focus of our approach [see also Froot et al. (1993)].

3. It is of interest to note that it is optimal for the buyer to owe money in the currency with the higher market interest rate. As explained in Ahtiala and Orgler (1995), this is due to the covered interest arbitrage condition, which lowers the forward exchange rate below the spot rate. 
the exporter's products as given. However, the freedom to choose the invoice currency can be of value to the buyers and increase their demand at any given price, giving the seller a competitive advantage.

The objective of this paper is to determine whether the choice of an invoice currency has value for the importer and demonstrates how that choice can be used by the exporter as a competitive device by combining exchange risk management with pricing. More specifically, our objective is to identify the situations in which the seller can take advantage of interest rate differentials across currencies as well as the buyer's exchange rate expectations and initial foreign exchange position. While we do not discuss the details of the bargaining process, we state the conditions under which the seller would gain from offering its customers a choice between payment in two or more currencies (e.g., the seller's currency and the buyer's currency), as opposed to insisting on payment in a single currency. Given the currency preferences of the buyer, the choice can lead to increased sales. Moreover, if the choice can be offered at little or no cost to the seller, given its currency positions and expectations, such a pricing policy can increase the seller's profits. The contribution of the invoice currency choice to the "bottom line" could be substantial, especially if the choice is between less common currencies with large transaction costs. A similar effect can be caused by great discrepancies between national interest rates, commonly involving substantial risks to the seller and/or the buyer.

The value of a currency choice for the buyer depends on its initial foreign exchange position and its exchange rate expectations. We analyze two scenarios:

(A) The alternative to choice is payment only in the seller's currency.

(B) The alternative to choice is payment only in the buyer's currency. In each of these scenarios there are two alternative situations:

(a) The buyer's expected future spot rate plus its risk premium is larger than the forward rate, adjusted for transactions costs.

(b) The buyer's expected future spot rate plus its risk premium is smaller than the forward rate, adjusted for transactions costs.

We derive the value of the choice for the buyer for each of these scenarios. For instance, in case (Aa) the choice has value over a required payment in the seller's currency only if the market interest rate in the buyer's currency is greater than that in the seller's currency and 
everything else is the same. The value increases with the commissions on forward transactions, which is particularly relevant for less common currencies. It declines if the buyer has a non-speculative open long position in the seller's currency or if the seller uses an implicit exchange rate higher than the spot rate in determining the price in the buyer's currency. These results, as well as those for the other scenarios, are derived in Section 2. They are driven by the fact that the forward exchange rate often deviates substantially from the expected future spot rate, and by transactions costs.

In making its pricing decisions, the seller would need information about the buyer's foreign exchange situation in order to take advantage of the value of a currency choice. Since this information is not readily available, the seller would do well to bring up the invoice currency issue when negotiating with the buyer the contract terms (price, credit, delivery, etc.). To evaluate the information obtained from this process, the seller has to proceed in the same way as in making an offer in a single currency.

In practice, exchange risk management is usually vested with the finance department, which quotes shadow rates in different currencies for use by the marketing or export department, reflecting the company's foreign exchange position and hedging costs. In many exporting companies, the finance department also purchases receivables from the marketing department at the quoted rates. When the finance department functions as a profit center, the costs and revenues from managing foreign exchange positions are debited and credited to the department.

The paper proceeds as follows: The model is presented in detail in the next section. In Section 3, we identify a four-way buyer classification which can be used as a guideline by the seller in establishing a currency choice policy. In Section 4, two numerical examples with arbitrary but realistic values show that the invoice currency choice can easily correspond to a 5-7-percent price cut. The concluding section of the paper analyzes the outcome of the above comparisons and evaluates the possibility of extending the choice to currencies other than those of the seller and the buyer.

\section{The Value of Choosing the Currency of Payment}

Let us analyze the determination of the value of invoice currency choice in a world characterized by bid-asked spreads on foreign exchange 
markets, risk adverse exporters and importers, and transaction costs. Importers sell their goods on their domestic market with their own value added, consisting of trade and/or manufacturing services, and face a declining demand curve, as is typically the case with industrial goods.

We assume for simplicity that the seller gives the buyer the choice of paying either in the seller's currency or in the buyer's currency, stating the prices in both currencies. At time (0), the seller contracts to deliver $x$ units of its product at a specified date for $y$ units of the seller's currency, or for $z$ units of the buyer's currency. Generally, the optimal $z / y$ is not equal to $e$, the spot price of the seller's currency in terms of the buyer's currency at the time of contract (0). Let $z / y=\gamma e$, where $\gamma e$ is the conversion rate, with $\gamma_{<}^{\geq} 1$ being the implicit conversion factor. As shown by Ahtiala and Orgler (1995), the value of $\gamma$ is determined by the seller's optimization process, and depends on the competition in the buyer's market, the seller's initial position in the buyer's currency, the risk and expected change of the spot price of that currency as assessed by the seller, and the cost of hedging a position in that currency. The value of $\gamma$ can be substantially above one, especially for unstable currencies, because of hedging costs. It can be below unity if the seller has a non-speculative long position in the buyer's currency. Payment in either currency is due on date $v$.

The value of a currency choice to the buyer is determined by comparison to a mandatory payment in a single currency - that of the seller or the buyer - determined by the seller. The buyer has to make its choice at point ( 0 ). If it chooses the seller's currency, it can: (a) cover its position on the forward market at the offered forward rate of $e_{F}$, plus commissions, (b) match its forthcoming payment against a nonspeculative long position in the seller's currency, if any, at the shadow price of $e_{F} \eta$ (where $\eta_{>}^{<} 1$ is a factor by which the cost of the seller's currency can deviate from $e_{F}$, to be further explained later), or (c) leave an open short position. The buyer chooses the last alternative (c) if $e_{F}$ exceeds its expected spot rate at $v$ (including spot commissions), or $E\left(e_{v}\right)$ by more than its idiosyncratic risk premium $\beta$, as shown in figure 1.

Figure 1 demonstrates the buyer's decisions in the absence of transactions costs. If $e_{F}<E\left(e_{v}\right)^{*}$, i.e., the forward rate (without commissions) is smaller than the buyer's expected future spot rate without commissions $E\left(e_{v}\right)^{*}$, the buyer covers all short positions. If 


\begin{tabular}{|c|c|c|c|}
\hline \multicolumn{2}{|c|}{$E\left(e_{v}\right)^{*}-\beta \quad E\left(e_{v}\right)^{*}$} & \multicolumn{2}{|c|}{$E\left(e_{v}\right)^{*}+\beta$} \\
\hline Leave open all long positions & & & Leave open all short positions \\
\hline \multicolumn{2}{|c|}{ Cover all short positions } & \multicolumn{2}{|c|}{ Cover all long Positions } \\
\hline & $\begin{array}{l}\text { Gray area } \\
\text { for long } \\
\text { positions }\end{array}$ & \multicolumn{2}{|l|}{$\begin{array}{l}\text { Gray area } \\
\text { for short } \\
\text { positions }\end{array}$} \\
\hline
\end{tabular}

Figure 1.-The Buyer's Choice of Foreign Currency Positions in the Absence of Transactions Costs

$e_{F}<E\left(e_{v}\right)^{*}-\beta$, the forward rate is so much below the expected future spot rate that the buyer does not find the cover of its long positions worth the cost so it leaves them open. If $e_{F}>E\left(e_{v}\right)^{*}$, the buyer covers all long positions, and if $e_{F}>E\left(e_{v}\right)^{*}+\beta$, it leaves open all short positions. The interval $E\left(e_{v}\right)^{*}+\beta>e_{F}>E\left(e_{v}\right)^{*}$ is a gray area for short positions, and that of $E\left(e_{v}\right)^{*}>e_{F}>E\left(e_{v}\right)^{*}-\beta$ is a gray area for long positions, where the buyer weighs the value of the cover against its cost. It is in these intervals that savings can be made by matching. Obviously, the gray area approaches zero as $\beta$ approaches zero.

In the general case including transactions costs, if the buyer has a choice of invoice currencies, it chooses the cheapest of the above alternatives, or $\min \left[e_{F} \eta ; E\left(e_{v}\right)+\beta ; \gamma e\right]$. The first expression is the shadow cost per unit of the seller's currency of alternatives (a) and (b), the second is that of (c), and the third represents payment in the buyer's currency. In these expressions, $e_{F}$ and $e$ are market prices, and $E\left(e_{v}\right), \beta$, and $\eta_{<}^{>} 1$ are the buyer's own idiosyncratic variables. The value of the choice $V_{i}$ can be expressed as follows:

$$
V_{1}=\frac{\max \left\{\left\{\min \left[e_{F} \eta ; E\left(e_{v}\right)+\beta\right]-\gamma e\right\} y ; 0\right\}}{R_{B}^{v-n}},
$$




$$
V_{2}=\frac{\max \left\{\left\{\gamma e-\min \left[e_{F} \eta ; E\left(e_{v}\right)+\beta\right]\right\} y ; 0\right\}}{R_{B}^{v-n}} .
$$

The value is $V_{1}$ if the alternative to the choice is payment only in the seller's currency (when the buyer has only the alternative in the square brackets), and $V_{2}$ if the alternative is payment only in the buyer's currency, where $1 / R_{B}^{v-n}$ is the buyer's discount factor when the goods are delivered on date $n$ and payment is made on date $v$.

On the Euromarkets, the covered interest arbitrage condition has been found to hold sufficiently well to exclude profitable arbitrage opportunities for non-financial businesses [see McKinnon (1979)]. Hence,

$$
e_{F}=\frac{R_{B}^{v}}{R_{S}^{v}} e
$$

where $R_{B}=1+r_{B}$, and $r_{B}$ is the market interest rate per period in the buyer's currency; and where $R_{S}=1+r_{S}$, and $r_{S}$ is the market interest rate in the seller's currency.

If the buyer covers the payment on the forward market, it has to pay a commission in addition to the forward asked rate. This is the first scenario in equation (3) where $\eta$ takes on the value $1+c$ in which $c$ is the commission as a fraction of the forward rate $e_{F}$ :

$$
\eta=\left\{\begin{array}{cl}
1+c & \text { if the buyer covers on the forward market } \\
1+b \tau & \text { if the buyer hedges internally }
\end{array}\right\} .
$$

It should be noted that, nowadays, commissions are not charged on transactions in major currencies but the bank imputes its charges in its bid-asked spread. Yet, they still exist in the case of less common currencies, so we take them into consideration for the completeness of the analysis. They do not, however, affect the analytics.

It is possible, however, that the buyer can do better than cover at the forward rate, depending on its initial foreign exchange position. Suppose that the buyer has an initial non-speculative long position in the seller's currency where $E\left(e_{v}\right)>e_{F}>E\left(e_{v}\right)-\beta$ holds in the absence of transactions costs. This means that the buyer has decided not to cover because of the transactions cost in the forward market. In this 


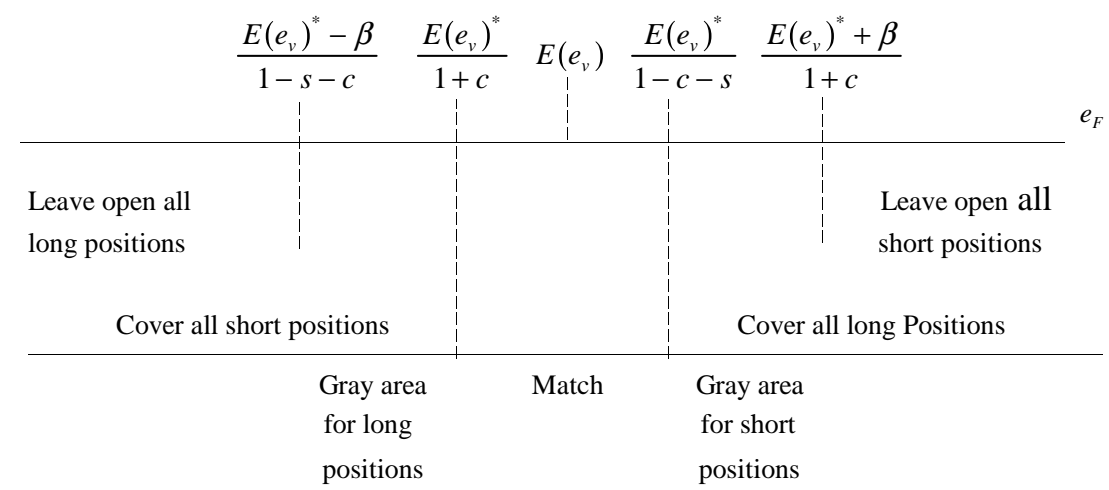

Figure 2.-The Buyer's Choice of Foreign Currency Positions in the Presence of Transactions Costs

situation, the buyer can use the forthcoming payment to cover part or all of that position. This lowers to the buyer the shadow price of the seller's currency $e_{F} \eta$, where $\eta=1-b \tau, b$ is a positive parameter, and $\tau=\max (g / y, 0)$. Note that $g \leq y$ is the buyer's initial net nonspeculative long position in the seller's currency up to $y$, i.e., the maximum amount that could be used for the transaction on hand. The parameter $b$ results from savings in transactions costs on the forward market. The long position can be covered at the forward bid price minus commissions, $e_{F}(1-s-c)$, where $s$ is the bid-asked spread as a fraction of the forward asked rate. In this case, this is the opportunity cost to the buyer of one unit of the seller's currency forward. In the presence of transactions costs, covering a long position is always optimal when $e_{F}(1-s-c)>E\left(e_{v}\right)$.

If the buyer has a short position, it has to pay $e_{F}(1+c)$ to cover that position, which is always optimal when $e_{F}(1+c)<E\left(e_{v}\right)$. Matching it avoids all spreads and commissions so that, instead of $e_{F}(1+c)$, the unit cost of foreign exchange is $e_{F}(1-s-c)$, implying $b=s+c$. On the other hand, if the buyer chooses to leave its position open, it will assume exchange risk exposure, apparently viewed as less costly than covering.

Figure 2 illustrates the buyer's foreign exchange choices with transactions cost. Compared to figure 1 , there is now a range of $(\mathrm{s}+2 c) e_{F}$, that is values from $E\left(e_{v}\right)^{*} /(1+c)$ to $E\left(e_{v}\right)^{*} /(1-c-s)$ where the buyer does not automatically cover any positions and matching is particularly profitable. In addition, the range from $E\left(e_{v}\right)^{*} /(1-c-s)$ to 
$\left[E\left(e_{v}\right)^{*}+\beta\right] /(1+c)$ (and from $E\left(e_{v}\right)^{*} /(1+c)$ to $\left[E\left(e_{v}\right)^{*}-\beta \rrbracket /(1-s-c)\right.$ on the long side) is a gray area where the buyer weighs the cover against the cost. Naturally, figure 2 is reduced to figure 1 as $s$ and $c$ approach zero.

It should be noted that a more complete model, determining the optimal invoice prices, was developed in Ahtiala and Orgler (1995). It consists of the seller's profit function expressing the present value of its sales revenues, in terms of its domestic currency, from sales in the two currencies, minus the cost of producing the goods sold. The exchange rate in the equations is the shadow exchange rate $\left(e^{S}\right)$, expressing what the foreign exchange is worth to the seller, as follows: $e^{S}=e_{F} \varepsilon$, where $\varepsilon=1+a \mu+b \tau^{S}$, and $\mu=\max \left[E\left(e_{V}\right)-e_{F}-\beta^{S} ; 0\right]$. The forward rate $e_{F}$ is determined by the covered interest arbitrage condition (Eq. 2 ).

The buyers' profit function consists of the revenues from sales minus the costs of the goods paid in the two currencies, in terms of the buyers' currency, where the shadow exchange rate is determined in the same basic way as $e^{S}$. Maximizing profit yields the demand functions of the good invoiced in the two currencies. This more elaborate model is beyond the scope of this paper, whose objective is to complement the above article and determine whether the introduction of the freedom to choose an invoice currency causes the demand functions to shift.

\section{Currency Choice and Buyer Classification}

The above analysis suggests that the potential benefit from invoice currency choice for a given seller depends on the conditions of the buyers. In the following analysis, we identify a four-way buyer classification which can be used as a guideline by the seller in establishing a currency choice policy.

\section{A. The Seller's Currency as a Benchmark}

In the following two cases, the alternative to choice is a mandatory payment in the seller's currency.

Case (Aa): $e_{F} \eta<E\left(e_{v}\right)+\beta$

In this case, payment in the seller's currency would justify complete coverage, which means that the relevant price in the seller's currency is 
$e_{F} \eta$. By substituting $e_{F}$ from equation (2) into equation (1a) we obtain:

$$
V_{1}=\frac{\max \left\{\frac{R_{B}^{v} \eta-\gamma R_{S}^{v}}{R_{S}^{v}} e \gamma ; 0\right\}}{R_{B}^{v-n}} .
$$

Thus, a choice has value to the buyer if $R_{B}^{v} \eta>\gamma R_{S}^{v}$. Assume, for example, that $\eta=1$, i.e., the forward commission is zero and the buyer has no initial non-speculative open long position in the seller's currency. Assume that $\gamma=1$, that is, the seller sets the price in the buyer's currency by multiplying the price in its own currency by the current spot rate. In this case, the choice has value if the interest rate in the buyer's currency exceeds that in the seller's currency. If, for instance, the interest rate differential is 3 percentage points, which is not uncommon, the value of a choice for payment six months after the contract is roughly 1.5 per cent of the value of the contract. When the inevitable commissions are added, the value increases to a level that cannot be overlooked. Naturally, a choice is equivalent to a price cut by the same percentage, possibly at little or no cost to the seller, since the price is $y / x$. This makes it possible to increase the price in the buyer's currency by this amount without hurting competitiveness. As indicated above, the value of a choice increases with the interest rate spread and with forward commissions $(\eta>1)$. On the other hand, it declines if the buyer has an initial non-speculative open long position in the seller's currency $(\eta<$ 1). In this case, the value of a choice declines by up to $V_{1}$, since by leaving the position open the buyer signalled that the cover is not worth the cost. The value of a choice declines also if the seller sets a higher price in the buyer's currency $(y>1)$.

Case $(A b): e_{F} \eta>E\left(e_{v}\right)+\beta$

We obtain from equation (1a):

$$
V_{1}=\frac{\max \left\{\left[E\left(e_{v}\right)+\beta-\gamma e\right] y ; 0\right\}}{R_{B}^{v-n}} .
$$

Hence, a choice has value to the buyer if the effective conversion rate $(y e)$ is lower than the future spot rate expected by the buyer, plus its 
risk premium. Since $E\left(e_{v}\right)$ and $\beta$ are idiosyncratic values of the buyer, $V_{1}$ is determined individually for each buyer.

The values of $E\left(e_{v}\right)$ and $\beta$ can be determined in the following way. Assume the buyer has a subjective probability distribution of the spot price of the seller's currency at the time of payment. Depending on the degree of its risk aversion, the buyer sets its risk premium $\beta$. In practice, this is expressed in a statement like: "At the time of payment, the dollar is likely to be 1.6 Deutsche marks. It is so unlikely to fall below 1.3 (or rise above 1.9) Deutsche marks that it is not worth the cost of covering a long (short) position at that rate. However, covering a short (long) position would be a bargain". This gives $E\left(e_{v}\right)$ the value of 1.6 and $\beta$ the value of .3.

\section{B. The Buyer's Currency as a Benchmark}

In the following two cases, the alternative to choice is a mandatory payment in the buyer's currency.

\section{Case (Ba): $e_{F} \eta<E\left(e_{v}\right)+\beta$}

We obtain the expression for $V_{2}$ by substituting $e_{F}$ from equation (2) into equation (1b). The value of a choice is the negative of equation (4). Thus, if $\eta=\gamma=1$, a choice has value if the interest rate in the seller's currency exceeds the interest rate in the buyer's currency. The comments made in the first case apply in reverse: an increase in $\gamma$ and a decline in $\eta$ now increase the value of a choice, with $\eta$ again being the maximum effect in the case where the buyer has an initial long position in the seller's currency. More generally, the seller can increase its price competitiveness by offering the buyer the possibility of paying in a currency in which the buyer has a positive net cash inflow. The seller may be able to do this at no cost to itself if it has an initial nonspeculative open short position in that currency, that is, it is either in the "match" area or the "gray" area for short positions in figure 2. It can then engage in the kinds of matching operations described above.

Case $(B b): \quad e_{F} \eta>E\left(e_{v}\right)+\beta$

The value of a choice in this case is the negative of equation (5). Thus, a choice has value if the effective conversion rate $(\gamma e)$ is greater than the buyer's expected future spot rate plus its risk premium.

The availability of currency choice causes the buyer's demand curve 
to shift upwards by the unit value of a choice, $V / x$, which makes it optimal for the seller to raise its prices [Ahtiala and Orgler (1995)]. In other words, if the seller finds that a choice has value for the buyer, it performs a new optimization based on this information to determine its prices. These results are driven by the fact that the forward exchange rate often deviates substantially from the expected future spot rate, and by transactions costs due to which it is generally not optimal to fully cover foreign exchange exposures.

In all four cases, the value of a choice depends on the buyer's variables which are unobservable to the seller. It has to evaluate them in the same way as when making an offer without an invoice currency choice. If the critical variable is $e_{F} \eta$, the seller can assess the opportunity cost of its currency to the buyer on the basis of the currency's forward rate, the bid-asked spread, and the commission. If the buyer expects the seller's currency to depreciate vis a vis the implicit conversion factor $\gamma$, the seller has to make assumptions about $E\left(e_{v}\right)$ and $\beta$ in the same way as in making the original offer. The implicit exchange rate offered has to be profitable for the seller, and the buyer will choose this currency if it is profitable also for the buyer.

\section{Numerical Examples}

Consider case B.a., where the alternative to a choice is payment only in the buyer's currency and $e_{F} \eta$ is the preferred alternative for payment in the seller's currency, i.e., covering is preferred to an open position. Suppose a U.S. exporter sells goods to a Danish importer for immediate delivery $(\eta=0)$. The price is 1000 dollars $(y)$ or 6890 Danish krone $(y e y)$ and is payable one year after delivery $(v=1)$. The spot exchange rate of a dollar $(e)$ at the time of delivery is 6.5 Danish krone. Thus, the implicit conversion factor is $\gamma=1.06$, i.e., the seller demands a premium of 6 percent over the spot price for assuming the exchange risk. The dollar interest rate is 10 per cent and the Danish krone interest rate is 8 per cent per annum $\left(R_{S}=1.1 ; R_{B}=1.08\right)$. The buyer has an uncovered receivable of 2000 dollars from earlier transactions which it can use to cover the dollar exposure of the current transaction so that $g=y$, which makes $\tau=1$. The retail value of the bid-asked spread on a one-year forward contract is .2 per cent and the bank's commission is .1 per cent $(s=.002 ; c=.001$, so that $b=.003)$, so that $\eta=1-.003=.997$. Substituting these values into the negative of equation (4) yields the 
value of a choice to the buyer, $V_{2}=488.7$ Danish krone, over 7 percent of the transaction, which is equivalent to a price cut of up to the same percentage (note that the buyer signaled, by not covering its initial position, that the cover is not worth the cost). Thus, the seller could raise its dollar price by up to this amount without hurting its competitiveness, thereby capturing the buyer's savings in transactions cost, $s+c$. Even with $\gamma=1, V_{2}$ equals over 2 per cent of the transaction, which certainly cannot be overlooked. ${ }^{4}$ Of course, if the alternative to a currency choice is payment only in dollars, the value of a choice would be zero.

Consider now case B.b., where the alternative to a choice is payment only in Danish krone, but $E\left(e_{v}\right)+\beta<e_{F} \eta$. That is, the buyer finds covering so costly that it considers an open position as the preferred alternative if payment is made in dollars. Suppose the buyer expects the spot dollar rate to be 6 Danish krone at the time of payment $\left(E\left(e_{v}\right)\right)$, and its risk premium $(\beta)$ is .5 krone so that $E\left(e_{v}\right)+\beta=6.5$. The value of $\gamma e$ is 6.89 , as in the previous example. Substituting these values into the negative of Eq. (5) yields $V_{2}=361$ krone, over 5 percent of the transaction. Of course, if the alternative to a currency choice is payment only in dollars, the value of a choice would be zero.

\section{Concluding Comments}

We first derived the value of an invoice currency choice to the buyer, and then identified the situations in which the seller can enhance its competitive position by taking advantage of the interest rate differentials in different currencies, the buyer's exchange rate expectations, and its initial foreign exchange position. An invoice currency choice is often a cheaper way to achieve a competitive advantage than a price cut, especially for less common currencies or when exchange rates are volatile. Alternatively, offering a currency choice enables the seller to raise its prices without hurting its competitiveness.

If the future spot rate expected by the buyer plus its risk premium is

4. It is of interest to note that it is optimal for the buyer to owe money in the currency with the higher market interest rate. As explained in Ahtiala and Orgler (1995), this is due to the covered interest arbitrage condition, which lowers the forward exchange rate below the spot rate. 
larger than the forward rate adjusted for transactions costs, a choice has value to the buyer over payment only in the seller's currency if, everything else equal, the market interest rate in the buyer's currency is greater than that in the seller's currency. That value increases when there are commissions on forward transactions. It declines if the buyer has a non-speculative open long position in the seller's currency, or if the seller uses an implicit conversion rate that is higher than the spot exchange rate in determining the price in the buyer's currency. If the alternative to a choice is payment only in the buyer's currency we have a mirror image: a choice has value if the market interest rate in the seller's currency is larger than that in the buyer's currency. The value is reduced when there are forward commissions. It increases if the buyer has a non-speculative open long position in the seller's currency or if the seller uses an implicit exchange rate that is higher than the spot rate in determining the price in the buyer's currency.

If the future spot rate expected by the buyer plus its risk premium is smaller than the adjusted forward rate, a choice has value over payment only in the seller's currency if the former rate is higher than the implicit conversion rate used by the seller in determining the price in the buyer's currency. Of course, the value of a choice declines as the implicit exchange rate gets higher. If the alternative to choice is payment only in the buyer's currency, the reverse holds. These results are driven by the fact that the forward exchange rate often deviates substantially from the expected future spot rate, and by transactions costs.

The analysis holds for any two currencies but is especially relevant for less-common currencies and when exchange rates are volatile. Therefore, the seller would do well to bring up the invoice currency issue when negotiating the contract terms (price, credit, delivery etc.) with the buyer. By indicating a currency preference, the buyer signals a currency in which it has a non-speculative long position or prefers to have a speculative short position. To differentiate between these cases, the seller has to proceed in the same way as in making an offer in a single currency since it does not know the buyer's other options. If the buyer has a non-speculative long position, the currency's forward rate and the bid-asked spread are available from published sources, and the commission (when relevant) can be assessed with considerable accuracy. If the buyer prefers to have a speculative short position, the seller needs to assess the future exchange rate expected by the buyer and the buyer's risk premium or their sum. The implicit conversion rate offered in the contract has to be profitable for the seller, and the 
currency is chosen if it is also profitable for the buyer.

Depending on its foreign exchange positions and flows, the seller may be able to offer the buyer a choice of payment in its preferred currency at a low or no cost to itself. In the best of circumstances, the seller may have an initial open short position in that currency so that both parties could avoid the exchange risks associated with open positions in other currencies. Alternatively, the seller and the buyer could save the cost of a "round trip" on the forward market, where the savings can be greater than in the two-currency case. Overall, this could be a more cost-effective way to improve competitiveness than cutting the price or improving credit terms. Alternatively, it could make a price rise possible without hurting competitiveness. Moreover, the seller can improve both its exchange risk position and its competitiveness multinationally by offering appropriate currency choices and prices to its suppliers and clients.

With small clients, negotiation costs can be high so that the seller may find it uneconomic to determine the value of a choice to each buyer. With such clients, the seller can use a menu of posted prices which includes a currency choice. Such a pricing policy does not increase the seller's profits directly but it will enhance its competitiveness.

\section{References}

Ahtiala, P., and Orgler, Y.E. 1995. The optimal pricing of exports invoiced in different currencies. Journal of Banking and Finance 19: 61-77.

Bilson, J. F. O. 1983. The choice of an invoice currency in international transactions. In J. Bhandari and B. Putnam (eds.). Economic Interdependence and Flexible Exchange Rates. Cambridge, MA: MIT Press.

Bilson, J. F. O. 1987. The ECU and the choice of an invoice currency. In R. Levich and A. Sommariva (eds.). The ECU Market: Current Developments and Future Prospects of the European Currency Unit. Lexington, MA: D.C. Heath \& Co.

Froot, K. A.; Scharfstein, D. S.; and Stein, J. C. 1993. Risk management: Coordinating corporate investment and financing policies. Journal of Finance 48: 1629-1658.

Hakkio, C. S. 1981. The term structure of forward premium. Journal of Monetary Economics 8: 41-58.

Hansen, L. P., and Hodrick, R. J. 1980. Forward exchange rates as optimal 
predictors of future spot rates: An econometric analysis. Journal of Political Economy 88: 829-853.

Hekman, C. R. 1981. The effect of trade credit and price level comparisons. The Review of Economics and Statistics 63: 526-532.

Hodrick, R. J. 1987. The Empirical Evidence on the Efficiency of Forward and Futures Foreign Exchange Market. Chur, Switzerland: Harwood Academic Publishers.

Magee, S. P., and Rao, R. K. S. 1980. The Currency of denomination of international trade contracts. In R. Levich and C. Wihlborg (eds.). Exchange Risk and Exposure. Lexington, MA: D.C. Heath \& Co.

McKinnon, R. I. 1979. Money in International Exchange. New York: Oxford University Press.

Shapiro, A. C., 1973. Optimal Inventory and credit-granting strategies under inflation and devaluation. Journal of Financial and Quantitative Analysis 8: 37-46.

Soenen, L. A., and Aggarwal, R. 1989. Cash and foreign exchange management: Theory and corporate practice in three countries. Journal of Business Finance and Accounting 16: 599-619. 